\title{
Rational prescribing: 30 years after
}

\section{Rob Moulds AO \\ Retired clinical \\ pharmacologist}

\section{Keywords}

drug information, drug policy, quality use of

medicines

Aust Prescr 2021;44:116-7 https://doi.org/10.18773/ austprescr.2021.026
Thirty years ago, there was an event that was to have a profound effect on the quality use of medicines in Australia. This was a workshop entitled 'Rational prescribing: the challenge for medical educators'. The workshop was jointly convened by the Consumers Health Forum and the Australasian Society of Clinical and Experimental Pharmacologists (ASCEPT). It was sponsored by the Australian Department of Health. Of importance, and rather revolutionary at the time, the workshop broke new ground by formally bringing together for the first time a consumer organisation and a professional organisation to discuss a topic that had until then been considered solely the province of health professionals. The proceedings of this important workshop were published in a special supplement of Australian Prescriber.

The rational prescribing of medicines is just as important today as it was 30 years ago. It is therefore useful to reflect on the successful - and less successful - outcomes of such an important meeting and how our experience since 1991 can help us continue to improve prescribing.

One major concern, which is still very much with us today, was the rise of antibiotic-resistant organisms and the importance of ensuring inappropriate antibiotic prescribing does not exacerbate the problem. Probably the other major concern in 1991 was the rapidly escalating government expenditure on pharmaceutical benefits. This concern is also still with us, but importantly the type of drugs causing the escalating costs has changed completely. Thirty years ago, the major costs arose from drugs still under patent protection and prescribed long term for large numbers of people, for example, statins and ACE inhibitors. Now, the major costs arise from very expensive drugs, nearly all biologicals, which are largely prescribed by specialists for much smaller numbers of patients often with rare diseases.

Probably the biggest success from the meeting was the impetus given to the development of a national drug policy for Australia. This resulted in the National Medicines Policy which includes the quality use of medicines. ${ }^{2}$ The meeting also contributed within a few years to the establishment of the Australian Medicines Handbook and the National Prescribing Service (now known as NPS MedicineWise). It reinforced the role of independent information provided through Therapeutic Guidelines and Australian Prescriber. Some of these activities which continue to support the quality use of medicines today might not have come about without the vital initial support gained from the discussions and recommendations at the workshop.

The workshop recommended that all medicines should have consumer product information. This was implemented shortly after the meeting. The recommendation that independent information about therapeutics should continue to be provided to health professionals is evidenced by the longevity of Australian Prescriber. The workshop also recommended that drug utilisation reviews should be encouraged as widely as possible.

There were recommendations for the development of undergraduate and postgraduate core curricula in clinical pharmacology and the expansion of clinical pharmacology as both an academic and clinical specialty. These recommendations were also largely implemented over the subsequent few years although perhaps not quite as successfully as a few of the enthusiasts from ASCEPT might have hoped.

It is clear that the workshop was a great success when judged on how many of the recommendations came to fruition. What might the main topics for discussion be if such a meeting were to be held again today?

One dilemma is how to ensure essential independent drug information and therapeutic advice are available free of charge to all healthcare professionals. This is fundamentally important to enable up-to-date guidelines for antibiotic therapy as part of essential antimicrobial stewardship programs. However, independent information is equally as important for managing many other problems. Examples include minimising the use of opioids in the management of chronic non-cancer pain, ensuring a capped resource such as immunoglobulin is used appropriately, and ensuring that expensive biological drugs for conditions such as macular degeneration, chronic inflammatory diseases and neoplastic conditions are prescribed to only those patients who are likely to benefit.

How to provide information that is independent may be an insoluble dilemma. External funding inevitably compromises independence while selffunding inevitably excludes those unwilling to pay for information. Health professionals often have to look in several different places to find the information they require. It might well be appropriate that Australian Prescriber, Therapeutic Guidelines, the Australian Medicines Handbook and NPS MedicineWise all 


\section{<ustralian Prescriber}

VOLUME 44 : NUMBER 4 : AUGUST 2021

have different governance and funding models. However, it would seem timely for discussions to occur about whether or not other structures might better support rational prescribing in the future. The Department of Health has recently reviewed the activities of NPS MedicineWise. ${ }^{3}$

One question is whether or not a national formal assessment of medical students' prescribing skills should be a requirement for the accreditation of all medical schools by the Australian Medical Council. ${ }^{4}$ Another topic well worth discussion is how best to involve medical specialists and their peak bodies in ensuring the guidelines developed within their specialties incorporate quality use of medicines. It is important to ensure that the movement towards 'personalised' medicine does not morph into 'idiosyncratic' medicine.

Given these questions, it may be timely for a future workshop to review the quality use of medicines part of the National Medicines Policy. ${ }^{5}$ Rational prescribing remains a challenge in the $21^{\text {st }}$ century. $<$

Conflicts of interest: Rob Moulds is a medical advisor to the Partnership Program of Therapeutic Guidelines Ltd and is also a medical advisor to Health Education Australia Ltd.

\section{REFERENCES}

1. Rational prescribing: the challenge for medical educators Aust Prescr 1991;14: Suppl 1.

2. Australian Government Department of Health and Ageing. National Medicines Policy 2000. Canberra: Commonwealth of Australia; 1999. https://www1.health.gov.au/internet/ main/publishing.nsf/Content/national-medicines-policy [cited $2021 \mathrm{Jul} 1$ 1]

3. Hunt G. Response to the Review of the Quality Use of Medicines Program's Delivery by the National Prescribing Service. https://www1.health.gov.au/internet/main/ publishing.nsf/Content/qum-nps-review [cited $2021 \mathrm{Jul} 1]$
4. Harrison C, Hilmer S. The Prescribing Skills Assessment: a step towards safer prescribing. Aust Prescr 2019;42:148-50. https://doi.org/10.18773/austprescr.2019.050

5. McLachlan AJ, Aslani P. National Medicines Policy 2.0: a vision for the future. Aust Prescr 2020;43:24-6. https://doi.org/10.18773/austprescr.2020.007 